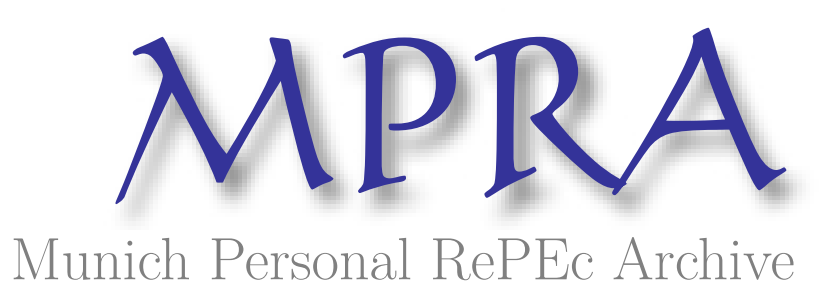

\title{
Distributional effects of congestion charges and fuel taxes
}

Eliasson, Jonas

Linköping University

May 2019

Online at https://mpra.ub.uni-muenchen.de/94328/

MPRA Paper No. 94328, posted 04 Jul 2019 06:22 UTC 


\title{
Distributional effects of congestion charges and fuel taxes
}

\author{
Jonas Eliasson \\ Linköping University, Linköping, Sweden \\ jonas.eliasson@liu.se \\ June 2019 \\ Forthcoming as chapter in in Vickerman and Börjesson (eds.): Encyclopedia of \\ Transportation, Elsevier.
}

\begin{abstract}
A common argument against car use taxes, such as congestion charges and fuel taxes, is that they hurt poor groups disproportionately. This chapter discusses this argument, explains methodological issues in distributional analyses and summarizes typical empirical findings. How distributional effects of a car use tax should be viewed depends on whether the purpose of the tax is fiscal or price-correcting (i.e. intended to make the cost of driving better reflect social costs). Overall, average payments of car use taxes tend to be approximately proportional to income, with a small tendency to regressivity in rich countries and progressivity in poor countries. However, there may substantial variation within an income group, which may be problematic if a tax primarily has a fiscal purpose. Distributional analyses of public revenue sources and public spending should in general be kept separate, since the definitions of what constitutes distributional neutrality often differ between taxes and expenditures.
\end{abstract}

Keywords: concentration index; congestion charges; distributional effects; equity; fuel tax; Suits index. 


\section{Introduction}

Fuel taxes and congestion charges have repeatedly been shown to be highly effective policy instruments to reduce traffic emissions and road congestion, respectively. However, a recurring argument against them is that they are claimed to fall disproportionately on the poor. This chapter analyses this argument. For brevity, I will refer to fuel taxes and congestion charges as "car use taxes". Most of the discussion in the chapter is just as relevant for other kinds of car-related taxes, such as vehicle taxes, parking charges and vehicle sales taxes.

The purpose of a car use tax matters greatly for what conclusions are drawn. Many car use taxes, in particular when fuel taxes were first introduced, have been fiscally motivated: they are simply a convenient way to raise revenues for various public expenditures. In such situations, it is clear that the taxes' distributional burden is relevant, and should be compared to other ways to raise public revenues, such as income, sales or property taxes. But more and more, car use taxes are seen as price corrections: they are motivated by a desire to make the cost of driving better reflect its total social cost, including externalities such as carbon emissions and road congestion. In other words, this kind of car use tax adjusts the price of driving to what it really should be; without it, driving is subsidized from a social point of view. From this perspective, it is much less clear in what sense distributional effects of car use taxes are relevant, and between which situations comparisons should be made. Prices are almost always the same for everyone, regardless of income or wealth, for two good reasons. First, it lets the individual decide for herself how to allocate her resources (money, time etc.) between different goods and services. Second, it leads to an overall efficient allocation of resources across the economy through supply-and-demand mechanisms. Desires for increased income equity is instead usually handled by taxation and social welfare systems. Accepting a default position where prices are, generally, equal for everyone (with a few deliberated exceptions), it is natural to argue that the distributional effects of corrective taxes - taxes which are introduced to make the prices "right" in the sense that they reflect full social costs are in fact essentially irrelevant. Indeed, allowing prices of car trips to be lower than their social cost (which they will be in the absence of car use taxes) effectively constitutes subsidies from society at large to car drivers, and these implicit subsidies accrue mostly to rich groups.

This being said, analyzing distributional effects may still be important, partly because most car use taxes have at least some fiscal motivation as well, and partly because any change in an existing price system causes transition costs when people adapt to the new prices.

\section{Methodological questions}

When analyzing distributional effects of tax instruments, several methodological questions need to be considered, most of which have no clear-cut answers.

\subsection{Should revenue recycling be included in the analysis?}

The first question is whether the recycling of the revenues should be part of the analysis. It is important to realize that the distributional profile of a revenue-generating tax instrument is 
one thing, and the distributional profile of an expenditure scheme is something else. They can be analyzed either separately, or together as a single policy.

One answer is that it depends on the decision context. If the revenues will be spent on something that will be carried out in any case, it is natural to compare the distributional profiles of different possible tax instruments in isolation, leaving the distributional profile of the planned expenditure out of the analysis. On the other hand, if one is considering introducing an earmarked tax for a specific project which will not be undertaken otherwise say, a congestion charge necessary to fund an infrastructure investment - it may be natural to consider the distributional profile of the tax and the project together, as a single policy.

However, there is a strong argument for analyzing tax instruments and expenditure schemes separately, namely that the natural and conventional definitions of what constitutes "distributionally neutral" schemes are usually defined differently for taxes and for expenditures.

The most common definition of a distributionally neutral tax instrument is one which takes an equal share of everyone's income. A tax instrument is defined as progressive if it takes a larger share of rich people's income than of poor people's; the opposite is called a regressive tax. This notion is formalized in the Suits index, defined as $S=1-2 \int_{0}^{1} T(y) d y$, where $y$ is the cumulative share of total income and $T(y)$ is the cumulative share of the total tax burden ${ }^{1}$. The index is bounded between -1 and 1 . A flat-rate tax has Suits index 0 , a regressive tax has a negative Suits index and a progressive tax a positive index.

For public expenditures, on the other hand, the most common ${ }^{2}$ definition of a distributionally neutral scheme is one which gives an equal absolute amount (or value) to everyone, a socalled lump sum distribution. An expenditure scheme is defined as progressive if it gives a larger amount per capita to poor people than to rich people, and regressive if it is the other way around. This notion is formalized in the concentration index, defined as $C I=1-$ $2 \int_{0}^{1} s(x) d x$ where $s(x)$ is the share of total spending accruing to the poorest $x$ percent of the population. The concentration index is also bounded between -1 and 1 , just as the Suits index. If all citizens receive the same amount (lump sum spending), the index is zero. Progressive spending (more is spent per capita on low income groups) yields a negative concentration index, and vice versa.

Now, note that the definitions of distributional neutrality are different for taxes and expenditures: a neutral tax takes an equal share of everyone's income, while a neutral spending scheme gives an equal absolute amount to everyone. This easily leads to paradoxical results when analyzing combinations of a tax and a revenue recycling scheme as a single policy. For example, combining a neutral tax (a fixed share of everyone's income) with a neutral expenditure scheme (a lump-sum redistribution) turns out to be a progressive policy

\footnotetext{
${ }^{1}$ In applications, data is usually given in discrete form for individuals or groups. Indexing these discrete observations by $i$, the Suits index is approximated by $S=1-\sum_{i}\left(T\left(y_{i}\right)+T\left(y_{i-1}\right)\right)\left(y_{i}-y_{i-1}\right)$.

2 There are studies and contexts, however, where neutral spending is defined as a scheme where each individual gets an amount proportional to her income.
} 
when seen as a combined policy, not a neutral one. It follows that it is easy to construct examples where a regressive tax combined with a regressive spending scheme is defined as a progressive policy when taken together and viewed as a single scheme, and vice versa: a progressive tax and a progressive spending scheme may be regressive when taken together. This is a strong argument for analyzing distributional effects of tax schemes and expenditure schemes separately, since this prevents this kind of confusion.

It is not uncommon that studies conclude that a car use tax is regressive, but together with lump-sum revenue recycling the total effect is progressive. This mixes the two different definitions of "progressive"/"regressive" explained above, ending up in a conclusion that is completely trivial on a closer look. Taking an equal share of everyone's income (a neutral tax) and handing the revenues back with a lump-sum distribution (neutral spending) is of course a highly progressive policy combination to start with. That a tax instrument is not regressive enough to make the combination with a lump-sum redistribution regressive is hardly surprising; if such a combination was regressive, the tax has to be extremely regressive in itself, effectively taking higher equal amounts in absolute terms from poor people than from rich people. Again, this shows that there are strong arguments for keeping distributional analyses of public revenue sources and public expenditures separate. In certain specific decision situations, however, it may still be natural to also consider a combined tax and spending scheme; the most common example is a car use tax earmarked for a project that will for certain not be undertaken otherwise.

\subsection{Income or expenditures as a measure of economic status?}

The second methodological question is how to define and measure individuals' available economic resources. One way is to simply use disposable income, i. e. the net sum of after-tax wages and transfers in a month or a year. However, this ignores that many people have other sources of money available to them. People may live off their savings or other sources of wealth, be supported by relatives (parents or a spouse), or have unregistered income sources. Moreover, some people may expect to have higher earnings in the future than they currently have, leading them to behave as if they borrow against their future income; this is especially relevant for students. Finally, income varies a lot between years, especially at the extremes. For example, someone selling a house or a company one year will have a very high income that particular year, but probably not nearly as high the next year. At the other extreme, some people may have extremely low incomes one particular year because they take a year off to study, take care of children or write a book, but in such cases their income are probably considerably higher other years. All this means that disposable income, in the usual sense, is not necessarily a full and fair measure of an individual's economic situation.

A way around this is to use individuals' expenditures as a proxy measure of their long-run available economic resources. An obvious drawback is that such studies must be based on survey data rather than registry data, and registry data usually gives much bigger and more precise data sets. Studies suggest that using expenditures rather than disposable income as a measure of economic resources tends to make tax instrument look more neutral - progressive taxes become less progressive, and regressive taxes less regressive. 


\subsection{Must behavioral adaptation be taken into account?}

A change in car use taxes will cause behavioral changes. This means that the welfare loss of a tax change will be accurately reflected neither by the total taxes paid after the change, nor by what would have been paid ignoring behavioral adaptation. The first alternative underestimates the welfare loss of a tax increase, since it ignores the loss in utility caused by adapting behavior, and conversely the second alternative overestimates the welfare loss since it ignores the possibility to adapting and hence partly avoiding the tax. It follows that only measuring the tax incidence, i.e. how much tax different groups pay, may give misleading conclusions, since this neglects the welfare loss of behavioral adaptation.

Clearly, it is preferable to use a proper welfare measure - the Marshallian or ideally the Hicksian consumer surplus (see the chapter by Harald Minken in this volume) - rather than simply using taxes paid. However, this is not always possible, since it requires forecasting behavioral adaptions to the tax. Fortunately, the error induced by neglecting adaptation costs is usually relatively small. If a tax is increased by some fraction $\alpha$ and the cost elasticity of demand is $\varepsilon$, the relative error of the welfare loss if adaption is ignored is $\frac{\alpha \varepsilon}{2}$. So, if a tax is increased by $\alpha=10 \%$ and the cost elasticity is $\varepsilon=-0.5$, the relative error is $2.5 \%$, which is negligible in most situations. Obviously, if the change is relatively large and demand elasticities are high and different across groups, the different between welfare loss and change in taxes paid may not be negligible anymore.

\subsection{Must second-order effects be taken into account?}

A change in car use taxes may change the prices of other goods and services as a second-order effect. This could mean that even individuals who do not travel by car are affected, since the prices of goods and services they consume may change. One case where this can matter is the price of public transport in poor countries, since diesel costs make up a substantial share of transit operating costs and poor groups make a much higher share of their trips by public transport than by car. This means that neglecting the second-order effect of a fuel tax increase on public transport prices, only considering the direct effect on driving costs, may underestimate the impact on poor groups.

\section{Two examples}

Consumption taxes are usually slightly regressive, since high income groups tend to spend a smaller share of their income on consumption, and more on e.g. savings. General sales taxes typically have Suits indices in the range -0.1 to -0.2 . Whether a consumption tax on a particular good is progressive or regressive depends on whether consumption of that good increases faster or slower than proportionally to income. In other words, a consumption tax will be regressive if the consumption elasticity with respect to income is lower than 1, and vice versa.

Broadly speaking, studies suggest that the income elasticity of car use is slightly lower than 1 in rich countries and slightly higher than 1 in poor countries. This means that car use taxes tend to be mildly regressive in rich countries but mildly progressive in poor countries.

Obviously, results will differ depending on the design of the tax, the context, what type of car use is taxed and so on. 
To illustrate some fairly typical results and how distributional analyses can be carried out, two empirical case studies are presented below: a fuel tax increase and a congestion charge. While the specific results obviously pertain to these specific cases, the reasoning is general, and the general findings are fairly representative for most studies.

\subsection{Example: Fuel tax}

The following case study shows results for an (approximately) 10\% increase of the Swedish fuel tax (reported in Eliasson, Pyddoke and Swärdh (2018)). Distributional impacts are calculated as welfare losses relative to disposable income, where incomes are taken from the tax registry. Driving distances are taken from the vehicle registry, and vehicles' fuel consumption from vehicle type registrations. Welfare losses are calculated using demand elasticities estimated separately for different combinations of income quartile and type of residential area (large cities, small cities and rural areas). Elasticities are medium-term, meaning that they consider changes in vehicle kilometers driven, but not changes in residential location or changes in vehicle characteristics (fuel consumption). Revenue recycling is not considered. Results are presented for combinations of income octiles and residential area.

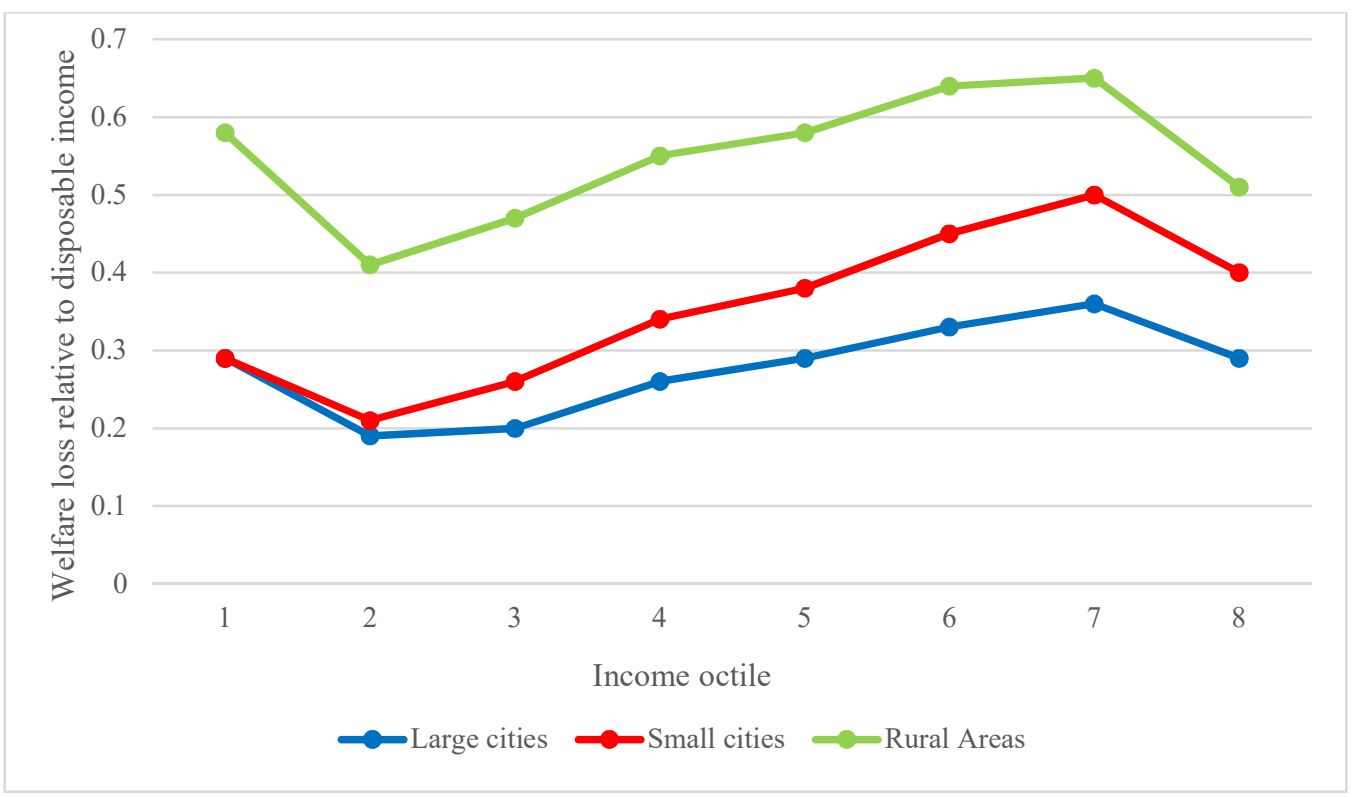

Figure 1 shows that the welfare loss increases as a share of disposable income for most of the income range (octile 2-7). The pattern is different for octiles 1 and 8, however. The result for octile 1 should be treated with caution; most incomes in this group are well below the threshold for social welfare in Sweden and therefore cannot really reflect individuals' real access to money. In octile 8 , incomes are so high that car use cannot reasonably increase in proportion to income. The regressivity/progressivity of the fuel tax increase is hence different across the income distribution: between octile 2 and 7 it is progressive, but in the low and high tails it is regressive. The Suits index for the entire income range shows that the fuel tax increase is slightly regressive overall; this is caused by the result for the highest octile. This also hints at why a fuel tax is often slightly regressive in rich countries, but progressive in 
poor countries: in rich countries, car use in the highest income groups tend to reach a saturation level above which car use only increases slowly when income increases further. This means that a fuel tax' share of income decreases in the highest income segments.

The variation in paid fuel tax across income groups is mostly due to differences in car ownership, and not so much due to differences in car owners' driving distances or vehicles' fuel consumption. This means that if one (for some reason) would consider only car owners, a fuel tax would be strongly regressive.

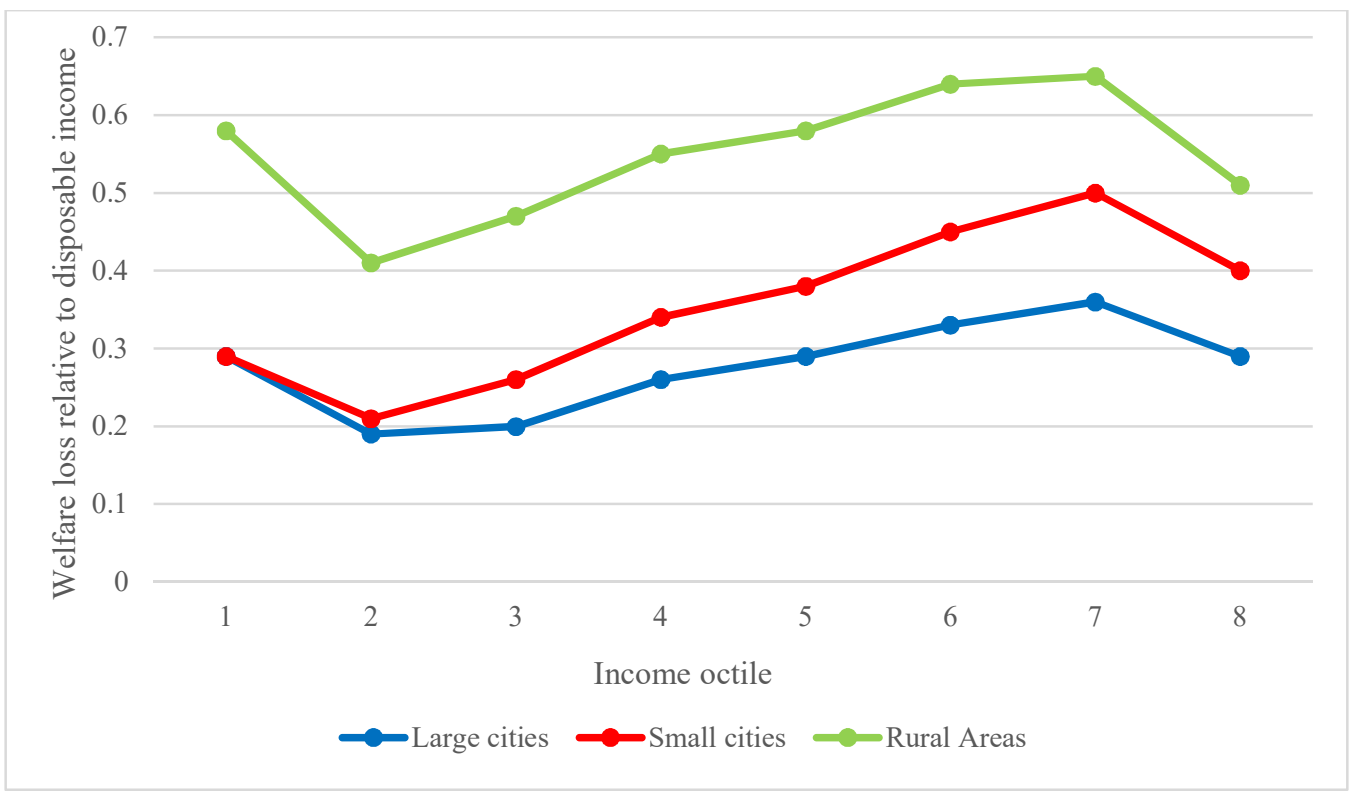

Figure 1. Welfare loss of the fuel tax increase, relative to income, by type of residential location. 


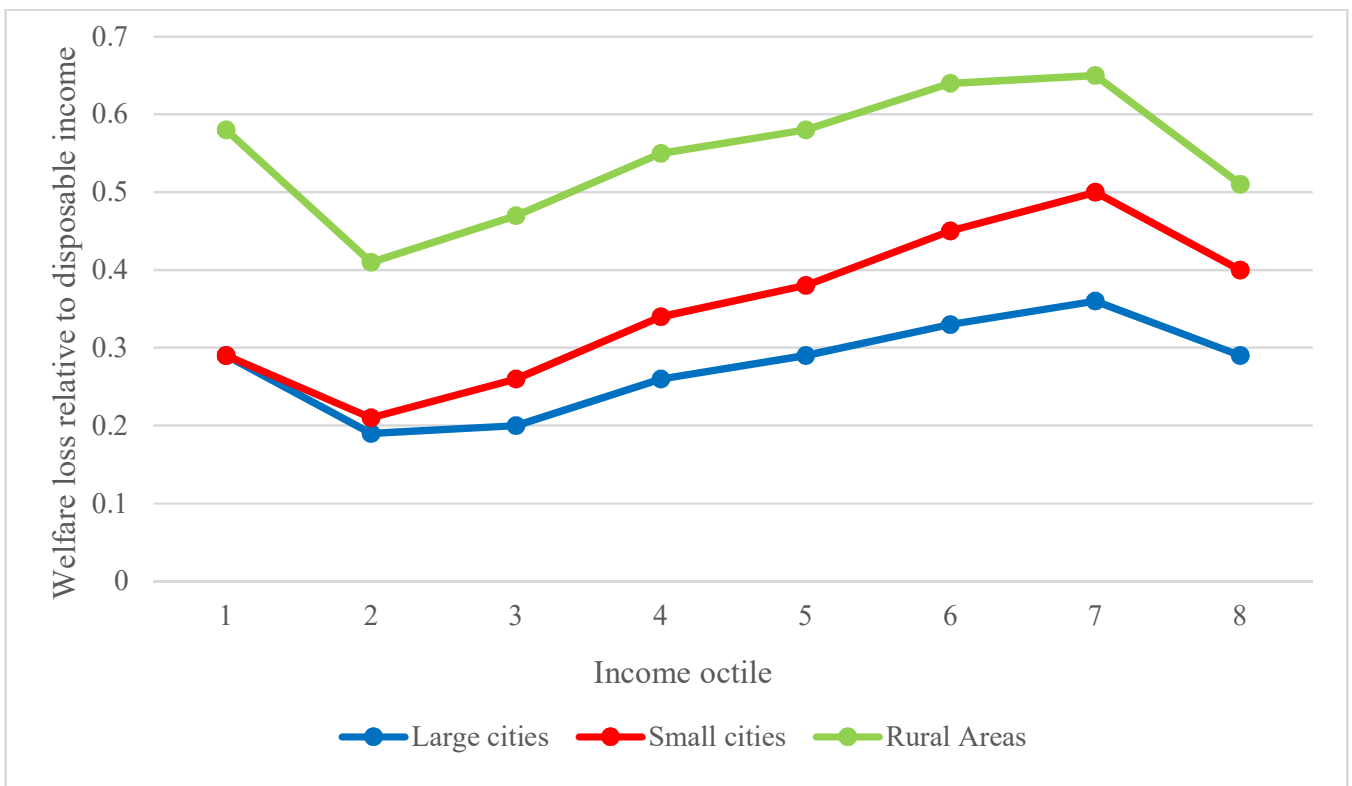

Figure 1 also shows that there are considerable differences between large cities, small cities and rural areas. A more detailed analysis of shows that residents in satellite cities, which serve as "suburbs" to a region's functional center, pay more in fuel taxes, and that such functional relationships between cities explains more of the variation than just population sizes.

However, these results only present average impact per group, which hides the fact that the variation within each income group is substantial. An income tax will, by definition, affect everyone with the same income in the same way. A car use tax is different: even if it is progressive "on average", there may still be individuals who are hurt disproportionately relative to their income. In fact, a more detailed analysis shows that the share suffering substantial welfare losses relative to their income is much higher in low income groups than in high income groups - despite that the average welfare loss relative to income is lower in the lower income groups. This is especially true for low income groups in rural areas. This may explain the feeling that car use taxes hurt the poor disproportionately: not that they are regressive on average, but that the share who suffer substantial welfare losses relative to their income are higher in lower income groups. That this point seems to be underappreciated is partly a data issue: exploring the variation within groups requires large data sets, and is often impossible without access to registry data, since survey- or modelling-based data sets are usually not sufficiently large.

The argument that members of a group should be affected equally is sometimes called "horizontal equity". How this argument should be applied in the context of car use taxes depends on the purpose of the tax, as argued in the introduction, since this implies how "groups" should be defined. If the purpose is primarily to generate public revenues, it is natural to define "groups" as income segments, and consider distributional effects across and within income groups. If the purpose is to correct the price of car trips, on the other hand, it is natural to define "groups" according to how much people drive, and distributional effects across and within income segments are much less relevant. 


\subsection{Example: congestion pricing}

Stockholm introduced congestion charges in 2006, first as a trial, and permanently from 2007. The charging system consisted of a cordon around the inner city, with charges varying between $2 €$ in peak hours and $1 €$ before and after the peaks (nights and weekends are free of charge). The system was slightly revised in 2016, when peak charges were increased and one charging point was added, but the analysis presented here refers to the original system.

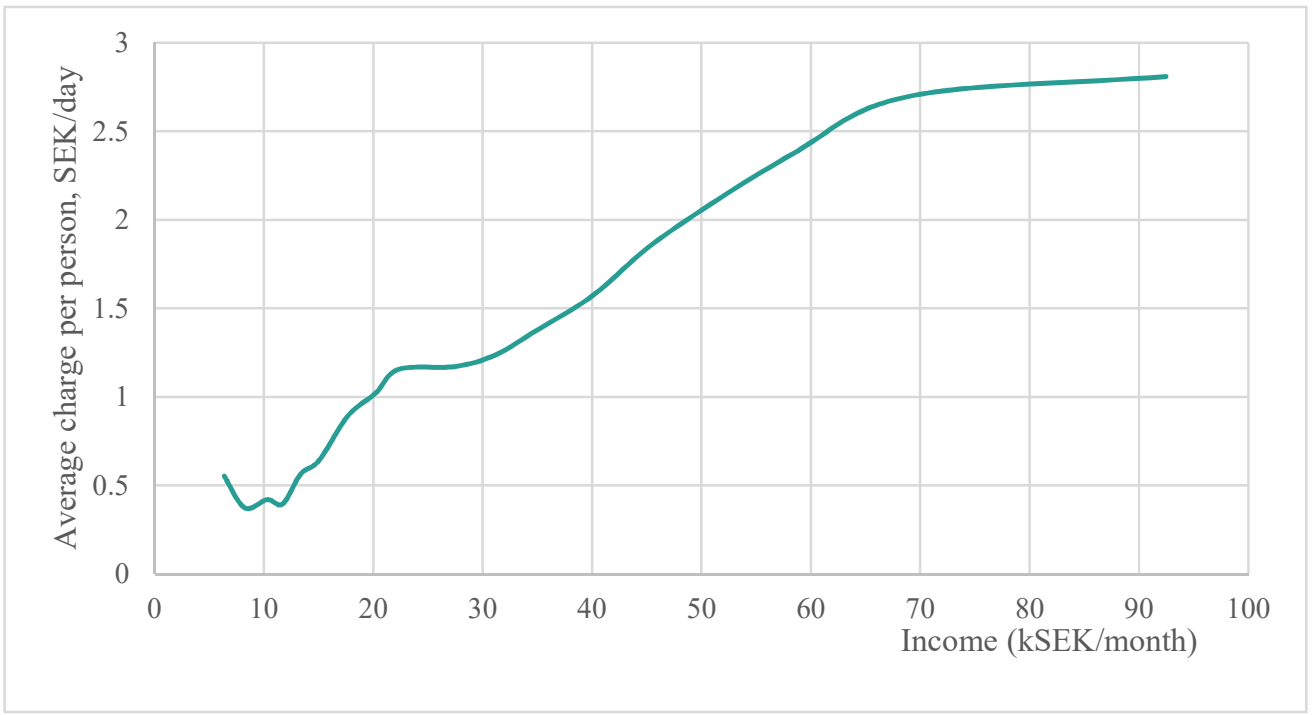

Figure 2 shows average congestion charges paid per person across the income range, and

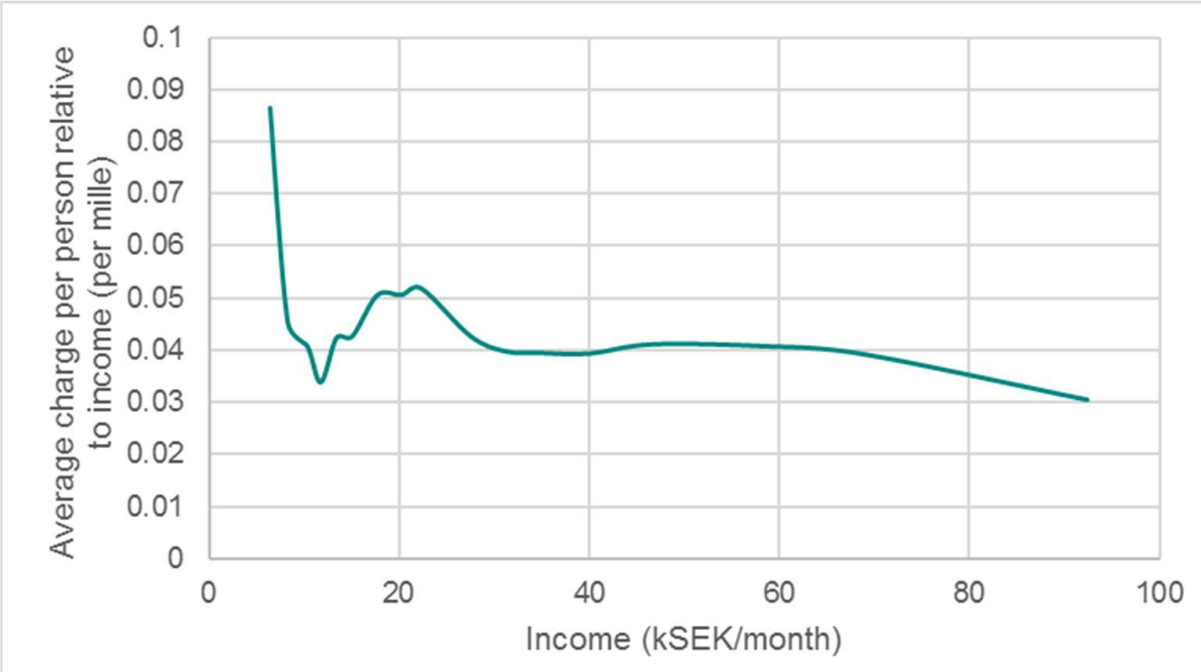

Figure 3 shows the same as a proportion of monthly income. The data comes from a travel survey (RVU 2015). Income is self-reported total household income before tax, divided by the number of adults in the household. Revenue recycling is not considered. The payment distribution is smoothed through kernel estimation (a generalization of the "moving averages" method). 


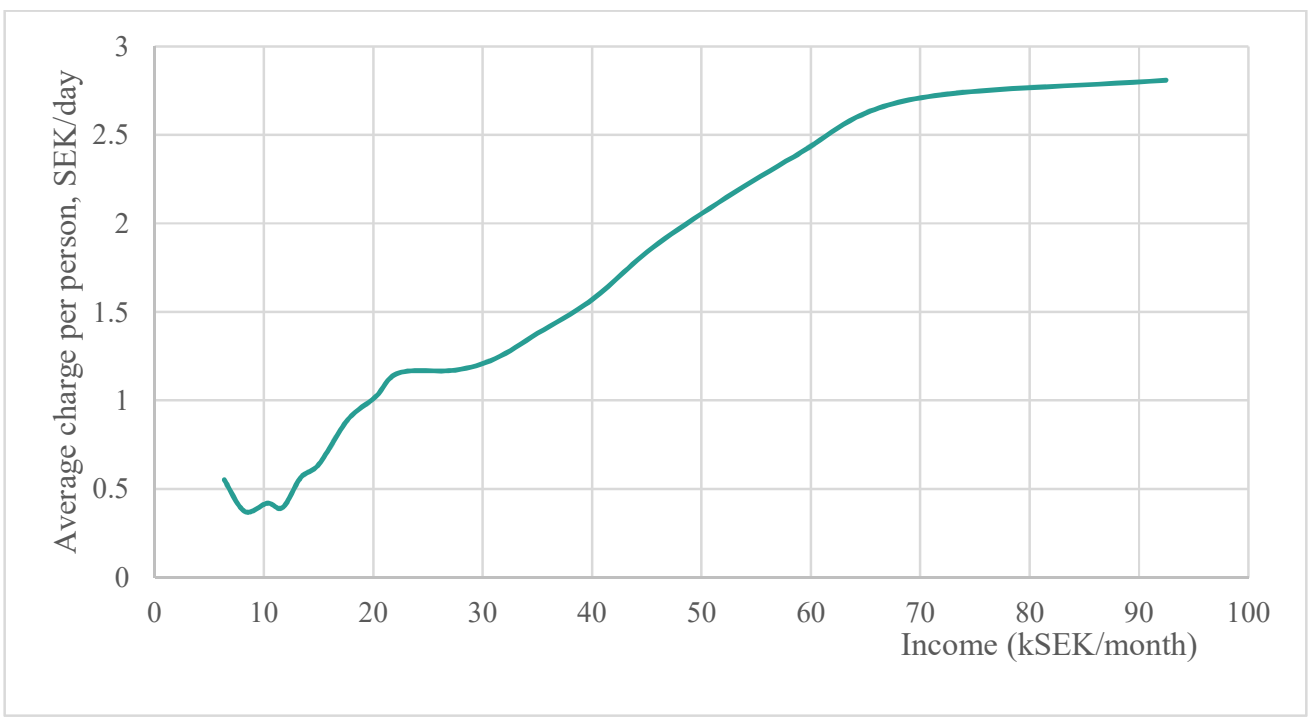

Figure 2. Average congestion charges paid per person and day (kernel estimation).

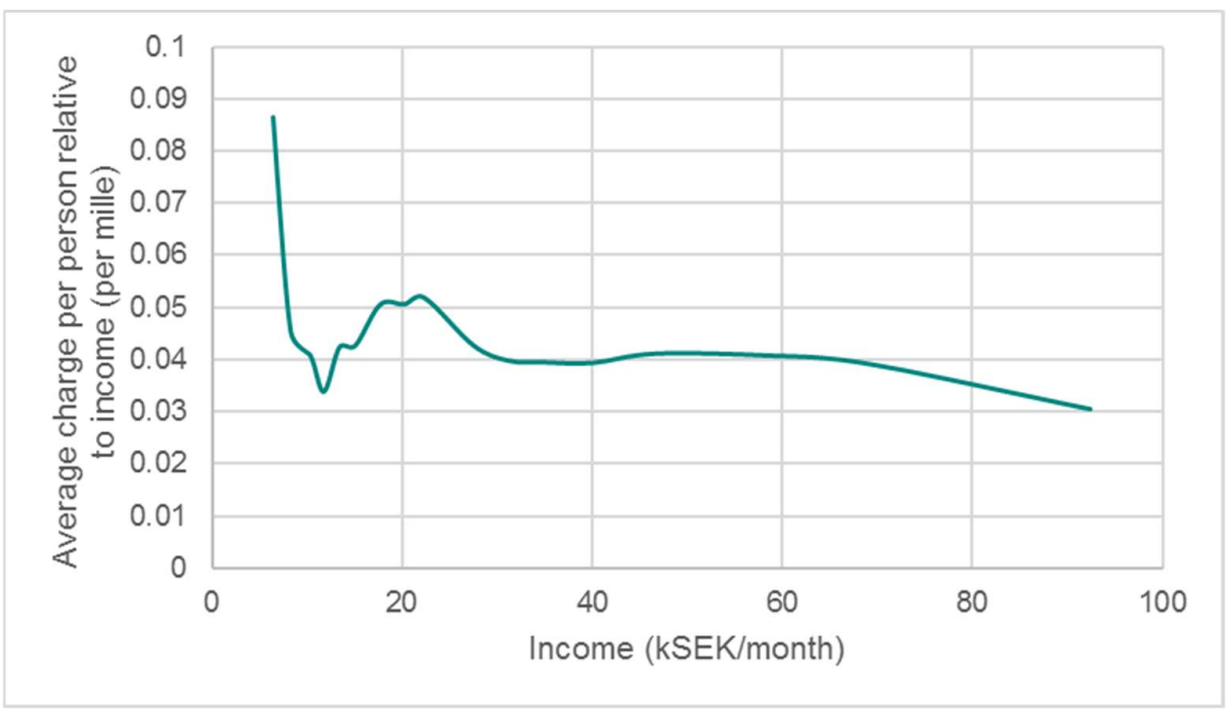

Figure 3. Average congestion charges paid per person and day relative to monthly income (per mille) (kernel estimation).

Average congestion charge payments per person are almost proportional to income, except for the lowest and highest incomes. As before, results for the lowest income groups should be treated with caution, since these incomes are so low that they can hardly reflect available economic resources. In the highest income range, it is as if car use almost reaches a saturation level where it no longer increases with income, and hence payments as a share of income falls somewhat for the highest income range.

It is evident from 


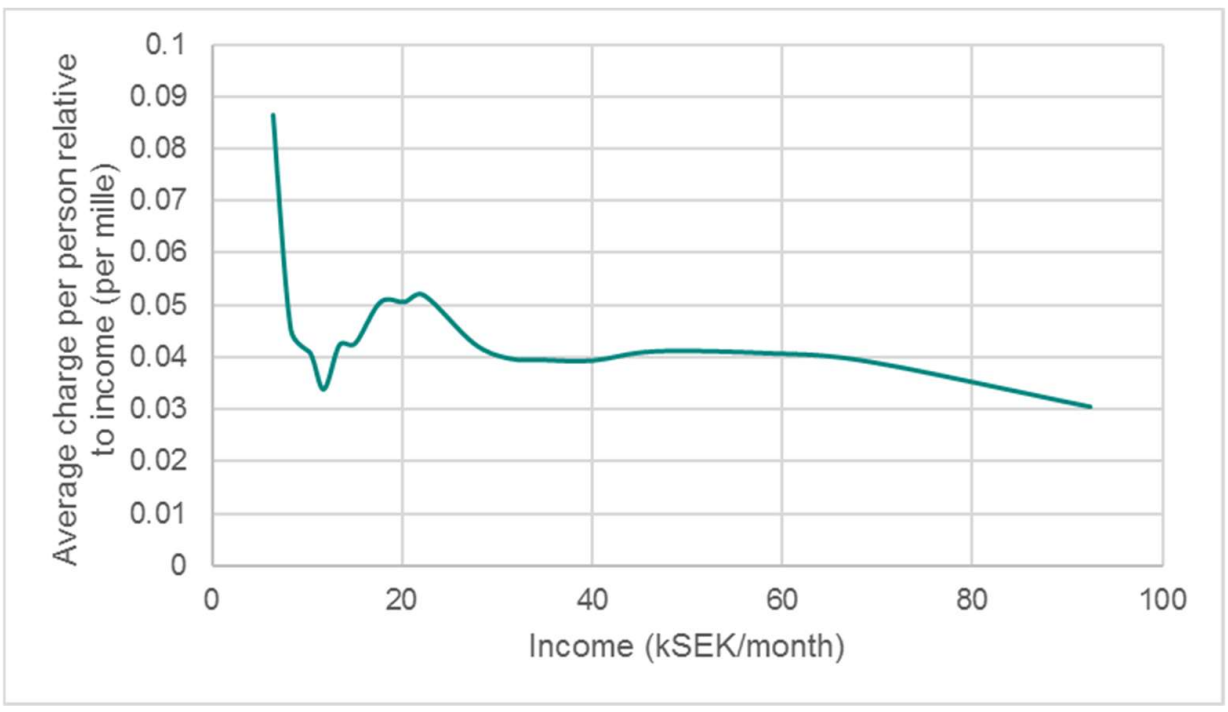

Figure 3 that the Stockholm charge is slightly regressive, since charge payments as a share of income falls slowly with income: the overall Suits index is -0.09 . It is also clear from the figures that the slight regressivity is almost entirely due the results at the extremes of the income range, whereas for most of the income range, charge payments are roughly proportionally to income. Just as for the fuel tax, however, these averages obscure the fact the variation with an income group is substantial.

Analyzing charge payments geographically (not shown here) shows that the congestion charge is more regressive for residents close to the charging zone - especially for residents within the inner city - while it is progressive for residents further away from the zone. This illustrates that the geographical distribution of socioeconomic groups and travel patterns matter, and hence results will differ between cities with different socioeconomic spatial distributions.

\section{A sample of empirical results}

The distributional effects of any consumption tax will depend on the local context, and car use taxes are no different. Table 1 shows a sample of empirical studies of distributional effects of fuel taxes, illustrating a representative range of results summarized by Suits indices. In rich countries, fuel taxes tend to be slightly regressive, but the regressivity decreases if expenditures are used instead of income as a measure of individuals' economic resources. In poor countries, fuel taxes tend to be progressive, and this progressivity also tends to decrease when expenditures are used as a measure of individuals' economic resources. Taking secondorder effects of fuel taxes into account affect results mostly to a small extent. 


\begin{tabular}{|l|c|c|c|c|l|}
\hline Country & $\begin{array}{c}\text { Income, } \\
\text { excl. second- } \\
\text { order effects }\end{array}$ & $\begin{array}{c}\text { Income, } \\
\text { incl. second- } \\
\text { order effects }\end{array}$ & $\begin{array}{c}\text { Expenditures, } \\
\text { excl. second- } \\
\text { order effects }\end{array}$ & $\begin{array}{c}\text { Expenditures, } \\
\text { incl. second- } \\
\text { order effects }\end{array}$ & Source \\
\hline France & -0.155 & -0.157 & -0.021 & -0.024 & Sterner (2012) \\
\hline Germany & -0.066 & -0.067 & 0.009 & 0.008 & Sterner (2012) \\
\hline Italy & & & -0.110 & -0.110 & Sterner (2012) \\
\hline Serbia & 0.187 & 0.172 & 0.066 & 0.055 & Sterner (2012) \\
\hline Spain & -0.086 & -0.086 & -0.002 & -0.002 & Sterner (2012) \\
\hline Sweden & -0.171 & -0.178 & 0.072 & 0.064 & Sterner (2012) \\
\hline $\begin{array}{l}\text { United } \\
\text { Kingdom }\end{array}$ & -0.123 & -0.125 & -0.003 & -0.004 & Sterner (2012) \\
\hline Texas (US) & -0.25 & -0.01 & & & Blackman, Osakwe \\
\hline Costa Rica & 0.09 & & & & $\begin{array}{l}\text { Eliasson, Pyddoke and } \\
\text { Swärdh (2018) }\end{array}$ \\
\hline Sweden & -0.03 & & & & Agostini and Jiménez \\
(2015)
\end{tabular}

Table 1. Suits indices for fuel taxes from empirical studies.

\section{Conclusions}

Car use taxes have repeatedly been shown to be very effective policies to reduce emissions and congestion. Few if any policies can compete in terms of effectiveness, and probably none in terms of economic efficiency.

The distributional consequences of car use taxes will obviously depend on their design and the local context. It is clear, however, that rich groups will pay considerably more per person than poor groups. Considering payments as a share of income, results are more mixed, but broadly speaking, average payments tend to be approximately proportional to income, but slightly regressive in rich countries and slightly progressive in poor countries. The overall regressivity tends be caused by the outliers: the highest and lowest income groups do not drive quite proportionally to their (registered) income level.

Variation within income groups is often substantial, however. Car use taxes also tend to place a higher burden on residents in rural areas, satellite cities and urban peripheries, which may counteract societal goals to make such areas more attractive. If the purpose of a car use tax is to generate revenues for public expenditures, variation with income groups, higher burdens in rural areas and slight regressivity may be viewed as serious problems. After all, it is difficult to defend that poor or rural people should contribute more than proportionally to public expenditures. In this respect, income or general sales taxes can be viewed as more fair, since these by construction takes an equal amount from everyone with the same level of income or consumption, respectively. 
However, it is much less clear that such distributional effects are relevant if the purpose of a car use tax is to correct the prices of car trips to make them better reflect their full social cost, by for example internalizing the cost of congestion or carbon emissions. Prices of goods and services are usually equal for everyone, for good reasons (most importantly that it leaves it up to individuals themselves to decide how to allocate their resources). Problems with inequitable income and wealth distributions are instead usually (and preferably) handled with general taxes and the social welfare system. Allowing prices of car trips to be lower than their social cost (which they will be in the absence of car use taxes) effectively constitutes subsidies to car drivers from society at large, and these implicit subsidies will overwhelmingly accrue to rich groups. From this perspective, the burden of proof from a distributional point of view lies not on those who want to introduce corrective car use taxes, but on those who defend a situation where car use is effectively subsidized by society. This is of course an even more pressing problem in countries where the price of car fuel is actually subsidized with public money.

Obviously, it can be difficult in practice to figure out whether a particular car use tax should be viewed primarily as a price correction or primarily as a source of public revenue.

Nevertheless, the two perspectives are important to keep in mind when drawing conclusions from an analysis.

\section{Further reading}

Agostini, C. A., \& Jiménez, J. (2015). The distributional incidence of the gasoline tax in Chile. Energy Policy 85, 243-252. https://doi.org/10.1016/j.enpol.2015.06.010

Arze del Granado, F. J., Coady, D., \& Gillingham, R. (2012). The Unequal Benefits of Fuel Subsidies: A Review of Evidence for Developing Countries. World Development 40(11), 2234-2248. https://doi.org/10.1016/j.worlddev.2012.05.005

Bento, A. M., Goulder, L. H., Henry, E., Jacobsen, M. R., \& von Haefen, R. H. (2005). Distributional and Efficiency Impacts of Gasoline Taxes: An Econometrically Based Multi-Market Study. The American Economic Review 95(2), 282-287.

Blackman, A., Osakwe, R., \& Alpizar, F. (2010). Fuel tax incidence in developing countries: The case of Costa Rica. Energy Policy 38(5), 2208-2215. https://doi.org/10.1016/j.enpol.2009.12.007

Casler, S. D., \& Rafiqui, A. (1993). Evaluating fuel tax equity: Direct and indirect distributional effects. National Tax Journal 46(2), 197-205.

Center for Public Policy Priorities. (2007). Who pays taxes in Texas? (No. No. 287). Center for Public Policy Priorities.

Eliasson, J. (2016). Is congestion pricing fair? Consumer and citizen perspectives on equity effects. Transport Policy 52, 1-15.

Eliasson, J., Pyddoke, R., \& Swärdh, J.-E. (2018). Distributional effects of taxes on car fuel, use, ownership and purchases. Economics of Transportation 15, 1-15. https://doi.org/10.1016/j.ecotra.2018.03.001 
Levinson, D. (2010). Equity Effects of Road Pricing: A Review. Transport Reviews 30(1), 33-57. https://doi.org/10.1080/01441640903189304

Santos, G., \& Rojey, L. (2004). Distributional impacts of road pricing: The truth behind the myth. Transportation 31(1), 21-42.

Sterner, T. (2012). Distributional effects of taxing transport fuel. Energy Policy 41, 75-83. https://doi.org/10.1016/j.enpol.2010.03.012 